DOI 10.37882/2223-2982.2020.04.37

\title{
ИСПОЛЬЗОВАНИЕ МАИЗМОВ В ЖИВОЙ РАЗГОВОРНОЙ РЕЧИ ЖИТЕЛЕЙ ГОРОДОВ ТУЛУМ И АКУМАЛЬ МЕКСИКАНСКОГО ШТАТА КИНТАНА-РОО
}

\section{THE USE OF MASIMOV IN COLLOQUIAL SPEECH THE INHABITANTS OF THE CITIES OF TULUM AND AKUMAL MEXICAN STATE OF QUINTANA ROO}

\section{Shakhnazaryan}

Summary: The territorial dialect of the Mexican national version of the Spanish language and the Mayan language coexist for more than 400 years on the territory of the Yucatan Peninsula. Despite the fact that the ancient Mayans language continues to lose its popularity every year, its influence on the Spanish language of the region can be seen at all levels of the language system. The purpose of this work is to identify the usage of maisms in lively conversation of the residents of the cities of Tulum and Akumal of the Mexican state Quintana Roo. The subject of the study is the lively spoken Spanish language of these cities. During our study, we used the methods of questionnaire, survey, direct observation, statistical and analytical methods. The results of a survey of local residents with an education level not lower than the bachelor show us the presence of usage of maisms in speech on everyday topics. The analysis of the obtained material showed that all the maisms can be divided into 6 groups after the Mexican linguist J.M. Lope Blanch (1979):

Group 1. Vocabulary known to absolutely everyone $(99-100 \%$ of respondents).

Group 2. Vocabulary known to almost all respondents (85-98\%).

Group 3. Vocabulary known to half of the inhabitants (50-84\%).

Group 4. Little-known vocabulary (25-49\%).

Group 5. Very little-known vocabulary (2-24\%).

Group 6. Almost unknown vocabulary (0-1\%) [Lope Blanch, 1979:34-35]. During our studying of the data, we came to the conclusion that there are semantic changes in the lexemes of the maisms corpus. Among them are words with a narrowing of the lexical meaning, words with an extension of the lexical meaning and words with a narrowing and extension of the meaning.

Key words: Spanish, dialect, maisms, lively speaking language, the Yucatan Peninsula, Quintana Roo.

\author{
Шахназарян Владимир Михайлович, \\ аспирант, Российский университет дружбы народов \\ vlad_shakhov@mail.ru
}

Аннотация: Территориальный диалект мексиканского национального варианта испанского языка и язык майя сосуществуют более 400 лет на территории полуострова Юкатан. Несмотря на то что язык древних майя с каждым годом продолжает терять свою популярность, его влияние на испанский язык региона прослеживается на всех уровнях языковой системы. Целью данной работы является выявить использование маизмов в живой разговорной речи жителей городов Тулум и Акумаль мексиканского штата Кинтана-Роо. Предметом исследования выступает живой разговорный испанский язык указанных выше городов. При проведении исследования нами были использованы статистический, аналитический методы, анкетирование, опрос, непосредственное наблюдение.

Результаты проведенного опроса местных жителей с уровнем образования не ниже бакалавра показывают наличие употребления маизмов в речи на обиходно-бытовые темы. Анализ полученного материала показал, что все маизмы корпуса можно разделить на 6 групп вслед за мексиканским лингвистом Х.М. Лопе Бланчем (1979):

Группа 1. Вокабулы, известные абсолютно всем (99-100\% респондентов). Группа 2. Вокабулы, известные практически всем респондентам (85-98\%). Группа 3. Вокабулы, известные половине жителей (50-84\%).

Группа 4. Малоизвестные вокабулы (25-49\%).

Группа 5. Очень малоизвестные вокабулы (2-24\%).

Группа 6. Практически неизвестные вокабулы (0-1\%) [Lope Blanch, 1979: 34-35].

В ходе изучения данных мы пришли к выводу, что существуют семантические изменения лексем корпуса маизмов. Среди них слова, в которых произошло сужение лексического значения, слова с расширением лексического значения и слова с сужением и расширением значения.

Ключевые слова: испанский язык, диалект, маизмы, живая разговорная речь, полуостров Юкатан, штат Кинтана-Роо.

хотя язык коренного населения не был потерян, он с каждым годом утрачивает свою популярность, оставляя при этом заметные «следы», которые в настоящее время прослеживаются на всех уровнях языковой системы диалекта мексиканского национального варианта испанского языка на территории полуострова. Необходимо отметить, что испанский язык Юкатана - это живой разговорный язык, который является средством обще- 
ния не только на территории одноименного штата, но и штатов Кампече и Кинтана-Роо, которые вместе формируют полуостров. На территории всех трех штатов также говорят на maya yucateco, одного из приблизительно 30 современных языков майя [England, 2001: 62].

Согласно данным Национального института статистики и географии и информатики Мексики, 6011202 жителя страны старше 5 лет говорят на каком-либо индейском языке. Науатль лидирует по числу - около 1400 000 говорящих. Далее следует майя полуострова Юкатан (maya yucateco) - 759000 носителей [INEGI, 2005]. Другими словами, язык майя - второй по числу говорящих на нем внутри страны. В отличие от других индейский языков, майя используется различными слоями общества на территории всех трех штатов и не только в индейских поселениях. Так, на языке майя говорят коммерсанты, домохозяйки, политики, рабочие, медики и т.д.

По наблюдениям известного мексиканского ученого Барбары Пфейлер (1999) можно сделать вывод о том, что на территории штата Кинтана-Роо существует три зоны с разным использованием языка: карибская часть штата - доминирование испанского и английского языков; центральная часть - консервативный лингвистический район майя; южная часть - доминирование испанского языка.

Именно развитый сельскохозяйственный сектор и высокий уровень миграции населения определяют культурные различия, связанные с использованием обоих языков на территории штата Кинтана-Poо [Pfeiler, 1999: 269].

По данным Института статистики, географии и информатики (INEGI), в 2010 году на территорию штата переехали 143899 человек, включая иностранных мигрантов (59 человек из 100 иностранных мигрантов - резиденты (ША) [INEGI, 2010].

Влияние языка майя отчетливо прослеживается на лексическом уровне, а именно в наличии и использовании маизмов в живой разговорной речи жителей штата Кинтана-Роо. Например, наречие chan (немного, чутьчуть, слегка, недостаточно): "Ella lo chan quiere" (Она его недостаточно любит) [Запись информантов]; существительное bоx (юкатанец, темнокожий, парень): “Оуе, boxito, ven acá!" (Парень, иди сюда) [Запись информантов]; наречие han (быстро, скореe): "Han vístete que ya es tarde" (Скорей одевайся, уже поздно).

Исследованием современного состояния испанского языка на территории полуострова Юкатан, в том числе использованием индихенизмов в речи жителей полуострова занимались известные мексиканские и американские ученые-лингвисты. Первым исследованием яв- ляется работа чешского ученого А.Р. Никла «Записки об испанском языке Юкатана, Веракруз и Тлашкла» (1930), в которой анализируются некоторые лексические заимствования, национально-культурные особенности грамматики и фонетики языка указанных штатов.

Мексиканский исследователь С. Баррера Баскес в 1937 году публикует статью «Маизмы и отголоски языка майя в испанском языке Юкатана», в которой, наряду с описанием влияния майя на фонетическом и синтаксическом уровнях, описывает маизмы, представленные на уровне морфологии. Позже ученый В.М. Суарес в своей работе «Испанский, на котором говорят на Юкатане» (1946) описывает особенности на всех уровнях. Однако данная работа не была признана фундаментальной ввиду малой географии исследования и недоработанной методики [Yakov, 1948: 178].

Наиболее полным исследованием испанского языка на территории полуострова Юкатан по праву считается работа известного мексиканского лингвиста-диалектолога Х.М. Лопе Бланча «Исследование испанского языка Юкатана» (1987), в которой были опубликованы данные, полученные в результате опроса 63 информантов. Он описывает лингвистическую интерференцию в области фонетики, лексики и грамматики. Однако, по нашему мнению, данное исследование не может отражать полную картину состояния испанского языка на территории штата Кинтана-Роо, поскольку опрос информантов проводился лишь в двух городах: Четумаль и Фелипе Карильо Пуэрто, к тому же некоторые данные уже устарели. Таким образом, исследование особенностей испанского языка штата Кинтана-Роо представляется нам неполным и недостаточным.

Для составления полной «картины» состояния современного испанского языка на территории данного штата нами была предпринята попытка его исследования в городах Тулум и Акумаль, штат Кинтана-Роо. Для получения результата нами был составлен опросник на основе модели, уже апробированной в исследованиях J.M. Lope Blanch (1987), R. Perez Aguilar (2002), G. Alcalá Phillips (2009). Однако нами существенно был доработан список лексем языка майя (200 лексических единиц) разных семантических групп: описание внешности и характера человека, его эмоционального и физического состояния, представители флоры и фауны, предметы быта, продукты питания и блюда, мифические персонажи из эпоса древних майя.

Считаем нужным отметить, что штат Кинтана-Роо по праву считается туристической меккой современной Мексики. Всё карибское побережье страны (более 500 километров) относится именно к достаточно молодому, а согласно Конституции страны, последнему штату Кинтана-Роо. Стремительное развитие туристической ин- 
фраструктуры, несомненно, повлияло на направления внутренней миграции населения, а также привлекло и продолжает привлекать трудовых мигрантов из менее благополучных стран, таких как Куба, Никарагуа, Гондурас и т.д. Смешение национальных вариантов испанского языка, территориальных диалектов мексиканского национального варианта, а также повсеместное использование английского языка, безусловно, сказывается на состоянии современного испанского языка штата. Как отмечено в работе лингвиста Г. Акала Филлипс «Лексические особенности испанского языка в городе Канкун», при таком уровне миграции можно говорить не только о замещении национально-культурных особенностей языка, привнесенных извне, но и исчезновении маизмов в речи жителей, вплоть до «смерти» языка майя. [Alcalá Phillips, 2009: 11 - 12].

В своем исследовании мы рассмотрели использование маизмов в живой разговорной речи коренных жителей штата Кинтана-Роо. С этой целью мы провели опрос в форме анкетирования. С информантами также проводилась беседа на разговорно-обиходную тематику.

Информантами выступили жители городов Тулум и Акумаль: 30 человек (мужчины и женщины) в возрасте от 24 до 55 лет с высшим образованием (бакалавры и магистры в сфере туризма и юриспруденции, PhD в области стратегического менеджмента).

Проведенный анализ показал, что лексические единицы языка майя, используемые в общении, можно раз- делить на 6 групп, предложенных лингвистом Х.М. Лопе Бланчем (1979):

Группа 1. Вокабулы, известные абсолютно всем (99100\% респондентов): alux (гном), bacal (сердцевина кукурузного початка, худой), ьох (юкатанец, темнокожий).

Группа 2. Вокабулы, известные практически всем респондентам (85-98\%): bak' (мясо), ch'uу (ястреб, карманник), dzul/tzul (любовь).

Группа 3. Вокабулы, известные половине жителей (50-84\%): kisin (дьявол), koló (глупец), k'ab (плечо, рука, ветка).

Группа 4. Малоизвестные вокабулы (25-49\%): kúuts ja (утка), maaná (сирота по матери), naaxche' (угли).

Группа 5. Очень малоизвестные вокабулы (2-24\%): am (паук), cháak (паук), holóm (шершень).

Группа 6. Практически неизвестные вокабулы (01\%): áak (черепаха), chi' (рот, слюни, пляж, побережье), kukutil (тело) и др. [Lope Blanch, 1979: 34-35].

Представим графически результаты проведенного эксперимента (см. рис. 1).

В ходе изучения полученных данных мы пришли к выводу, что есть изменения в семантике слов, их условно можно разделить на 3 группы:

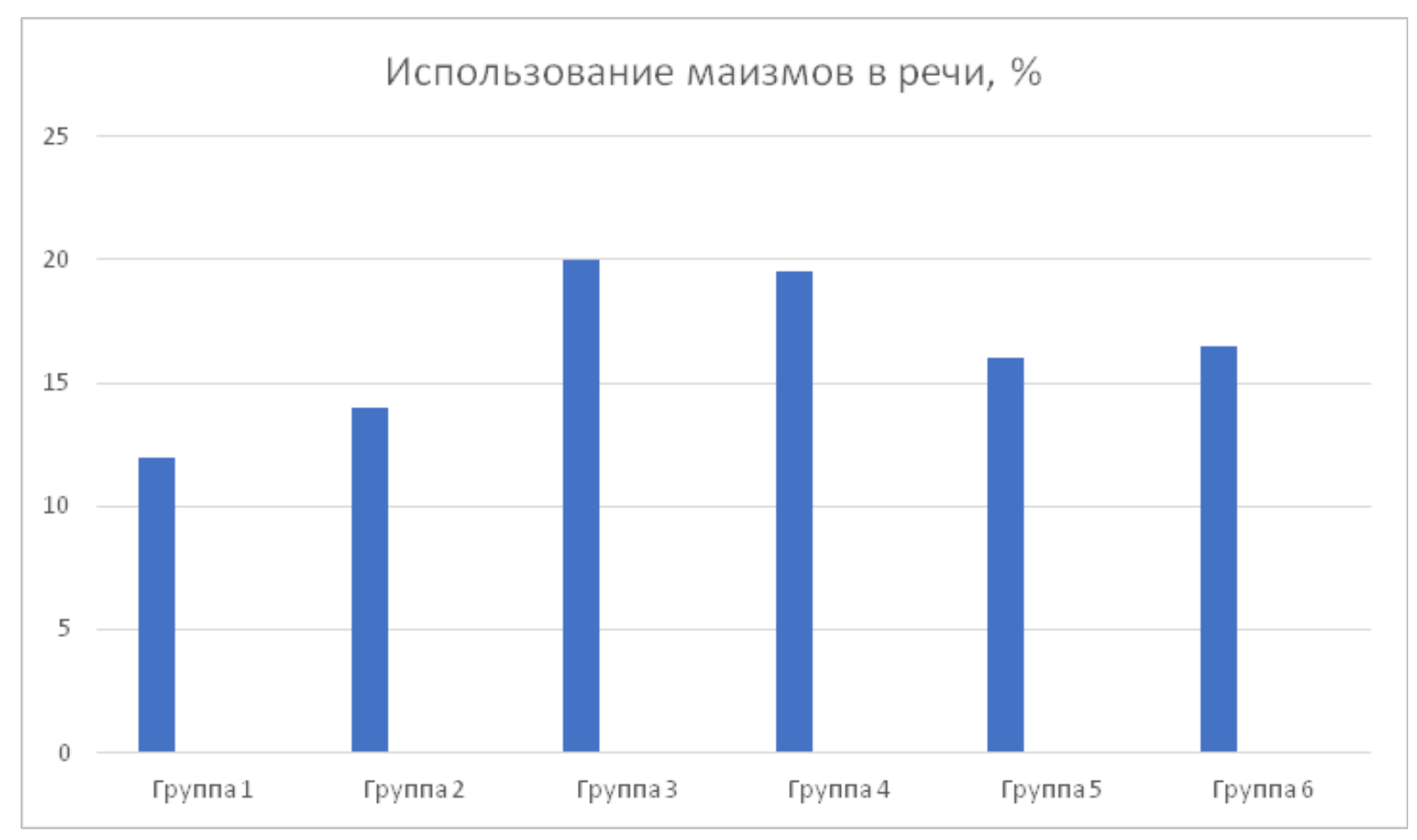

Рис. 1. Использование маизмов в речи 
- слова, в которых произошло сужение лексического значения:

\begin{tabular}{|c|c|c|}
\hline Лексическая единица & $\begin{array}{l}\text { Значения, отраженное в словаре языка майя полу- } \\
\text { острова Юкатан колониального периода (1970) }\end{array}$ & $\begin{array}{l}\text { Современное использование согласно слова- } \\
\text { рю Мауа - Español (2009) и результатам опроса }\end{array}$ \\
\hline bacal & $\begin{array}{l}\text { 1. Худой } \\
\text { 2. Сердцевина кукурузного початка }\end{array}$ & Сердцевина кукурузного початка \\
\hline buth & $\begin{array}{l}\text { 1. Полный человек } \\
\text { 2. Начинка для приготовления птицы }\end{array}$ & Начинка для приготовления птицы \\
\hline Tek & $\begin{array}{l}\text { 1. Сосуд, сделанный из какого-либо плода для хра- } \\
\text { нения тортильи } \\
\text { 2. Голова }\end{array}$ & $\begin{array}{l}\text { Сосуд, сделанный из какого-либо плода для } \\
\text { хранения тортильи }\end{array}$ \\
\hline mulix & $\begin{array}{l}\text { 1. Кудрявый человек } \\
\text { 2. Вид птиц с кудрявым оперением }\end{array}$ & Кудрявый человек \\
\hline pidz & $\begin{array}{l}\text { 1. Подслащенный напиток } \\
\text { 2. Непривлекательная девушка }\end{array}$ & Непривлекательная девушка \\
\hline ts'iris & $\begin{array}{l}\text { 1. Пупок, пупочный шрам } \\
\text { 2. Выпуклость } \\
\text { 3. Птичий зоб }\end{array}$ & Выпуклость \\
\hline xuxac & $\begin{array}{l}\text { 1. Корзина, сплетенная из лиан } \\
\text { 2. Торакс птиц } \\
\text { 3. Очень худой человек }\end{array}$ & $\begin{array}{l}\text { Корзина, сплетенная из лиан } \\
\text { Очень худой человек }\end{array}$ \\
\hline
\end{tabular}

\section{- слова с расширением лексического значения:}

\begin{tabular}{|l|l|l|}
\hline Лексическая единица & $\begin{array}{l}\text { Значения, отраженное в словаре языка майя полу- } \\
\text { острова Юкатан колониального периода (1970) }\end{array}$ & $\begin{array}{l}\text { Современное использование согласно слова- } \\
\text { рю Мауа - Español (2009) и результатам опроса }\end{array}$ \\
\hline alux & 1. Домовой & + Гном \\
\hline box & $\begin{array}{l}\text { 1. Юкатанец } \\
\text { 2. Темнокожий }\end{array}$ & $\begin{array}{l}\text { + Толстяк } \\
+ \text { Парень }\end{array}$ \\
\hline cuclim & 1. Жук & $\begin{array}{l}+ \text { Украшение из живого жука, оклеенного } \\
\text { стразами }\end{array}$ \\
\hline muuch & 1. Жаба & + Скупердяй \\
\hline oop' & 1. Поджаренные кукурузные лепешки & + Тосты \\
\hline p'urux & 1. Человек, сбольшим животом & + Беременная женщина \\
\hline хtabay & $\begin{array}{l}\text { 1. Мифический герой, принимающий образ женщи- } \\
\text { ны и стремящийся обмануть мужчин, чтобы приве- } \\
\text { сти их к гибели }\end{array}$ & $\begin{array}{l}\text { Плакса } \\
+ \text { Загрязненный воздух }\end{array}$ \\
\hline
\end{tabular}

\section{- слова с сужением/ расширением значения:}

\begin{tabular}{|l|l|l|}
\hline Лексическая единица & $\begin{array}{l}\text { Значения, отраженное в словаре языка майя полу- } \\
\text { острова Юкатан колониального периода (1970) }\end{array}$ & $\begin{array}{l}\text { Современное использование согласно слова- } \\
\text { рю Мауа - Español (2009) и результатам опроса }\end{array}$ \\
\hline loch' $^{\prime}$ & $\begin{array}{l}\text { 1. Горсть } \\
\text { 2. Земля или вода, заполняющая обе ладони } \\
\text { 3. Обниматься (-) }\end{array}$ & + Убаюкивать \\
\hline nohoch & $\begin{array}{l}\text { 1. Большой } \\
\text { 2. Главный (-) }\end{array}$ & + Толстый \\
\hline pa' & $\begin{array}{l}\text { 1. Стена } \\
\text { 2. Крепость, замок } \\
\text { 3. Ломать (-) }\end{array}$ & + Дом в деревне \\
\hline росс & $\begin{array}{l}\text { 1. Мечтатель } \\
\text { 2. Завидующий человек (-) }\end{array}$ & + +гун \\
\hline t'ucho $^{\text {1. Обезьяна-паук }}$ & 2. Призрак, приведение (-) \\
\hline
\end{tabular}


Дляпониманиямасштабовлексемныхтрансформаций маизмов обратимся к диаграмме (см. рис. 2).

Таким образом, использование маизмов в живой разговорной речи жителей городов Тулум и Акумль претерпевает изменения. По нашим данным семантика 20,5\% лексических единиц претерпела изменения на
современномэтаперазвитияязыка.Наибольшейгруппой являются слова с приобретенными лексемами (70\%), далее расположилась группа слов, утративших одну или несколько лексем (14,5\%). Наименьшее количество слов в третьей группе (12,5\%), в которой представлены слова, практически полностью изменившие свои значения.

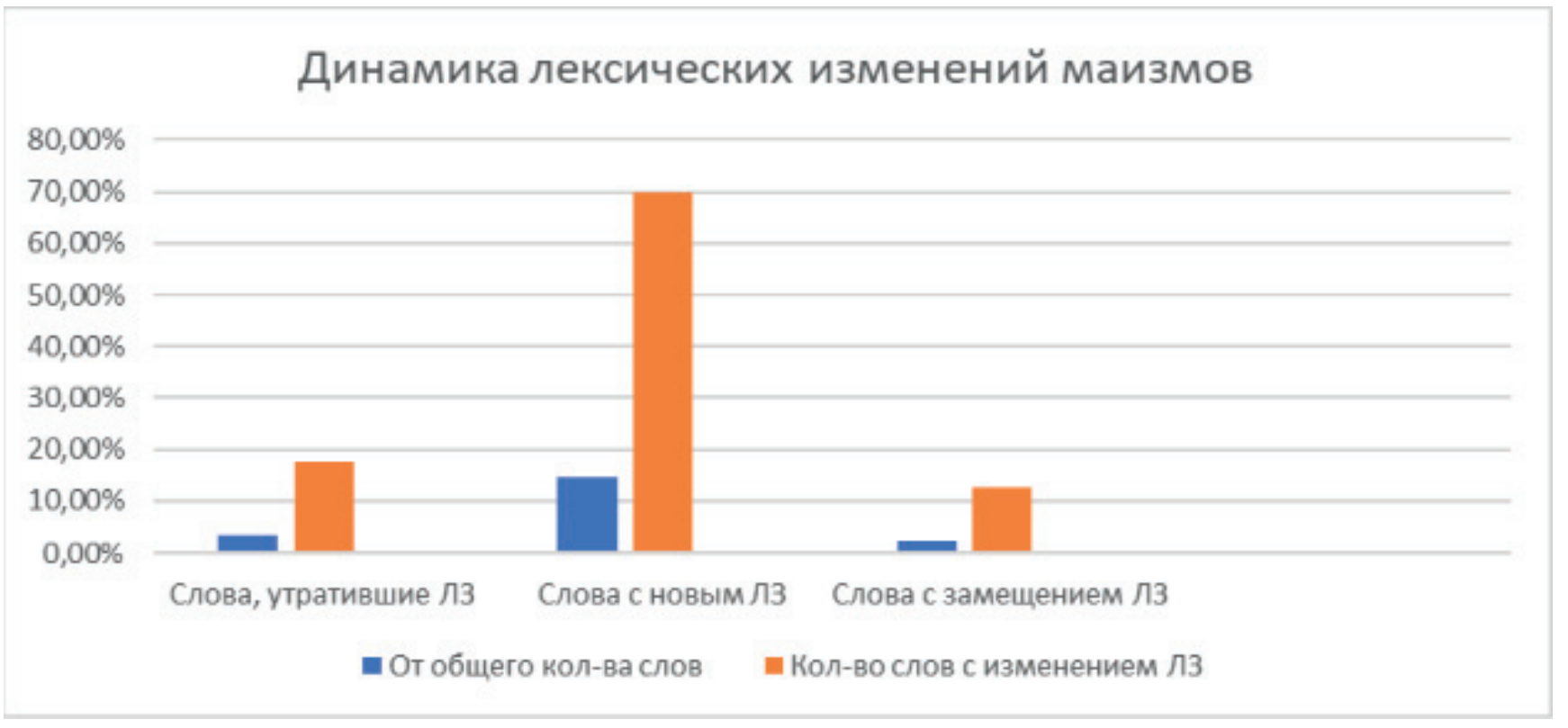

Рис. 2. Динамика лексических изменений маизмов

ЛИТЕРАТУРА

1. Alcalá Philips, G. Peculiaridades léxicas en el español de Cancún, Quintana Roo, - México, 2009.

2. England, Nora C. Introducción a la gramática de los idiomas mayas. Guatemala City: Colsamaj, 2001

3. Instituto Nacional de Estadística, Geografía e Informática (INEGI). II Censo de población y vivienda. [Электронный ресурс]. http://cuentame.inegi.gob.mx/ poblacion/migracion.aspx?tema $=\mathrm{P}$

4. Lope Blanch, J.M. Estudios sobre el español de Yucatán. México: UNAM, 1987

5. Lope Blanch, J.M. Léxico indígena en el español de México. México: El Colegio de México, 1979

6. Nykl, A. R. Notes on the Spanish of Yucatan, Veracruz, and Tlaxcala. //Modern Philology, 27(4). Cc. 451-460

7. Pérez Aguilar, R.A. El habla de Chetumal. Fonética, gramática, léxico indígena y chiclero. Chetumal: UQR00, 2002

8. Pfeiler, B. La situación sociolingüística en Yucatán, 1999 [Электронный ресурc]. http://www.mayas.uady.mx/articulos/situacion.html

9. Suárez, V.M. El español que se habla en Yucatán. 2 edición. Mérida: La Universidad de Yucatán, 1996

10. Yakov, M. El español que se habla en Yucatán. Apuntamientos filológicos de Victor M. Suárez. Mérida: La Universidad de Yucatán, 1948

11. Diccionario del español de México. [Электронный ресурc]. https://dem.colmex.mx/

12. Diccionario de elementos del maya yucateco colonial. México, UNAM, Coordinación de Humanidades, 1970

13. Diccionario Real Academia Española. [Электронный ресурс]. https://dle.rae.es/

14. Diccionario introductorio Español - Maya, Maya - Español, Gómez Navarrete, J.A. Chetumal, 2009

(c) Шахназарян Владимир Михайлович (vlad_shakhov@mail.ru)

Журнал «Современная наука: актуальные проблемы теории и практики» 